\title{
Differential Biosynthesis and Posttranslational Processing of Vasopressin and Oxytocin in Rat Brain During Embryonic and Postnatal Development
}

\author{
Miriam Altstein a and Harold Gainer \\ Laboratory of Neurochemistry, National Institute of Neurological and Communicative Disorders and Stroke, National \\ Institutes of Health, Bethesda, Maryland 20892
}

The biosynthesis and posttranslational processing of arginine vasopressin (AVP) and oxytocin (OT) peptides in the developing rat brain and pituitary were studied using antibodies and complementary separation methods that permitted a quantitative radioimmunoassay (RIA) analysis of precursor, intermediate, and completely processed forms of the peptides. Precursor forms of the peptides were first detected in rat brain as early as embryonic day (E) 15 for AVP and E17 for OT. Proteolytic cleavage products of the precursors were detected $1 \mathrm{~d}$ later for both peptides. AVP was present in a fully processed (amidated) form immediately (E16) and throughout fetal development. OT was cleaved from its precursor starting on $\mathrm{E} 18$ but remained in an intermediate (C-terminal extended) form until E21, when amidated OT was first detected in the pituitary. Hence, Pro-AVP processing in the fetus was immediate and complete, whereas Pro-OT processing in the fetus was much slower and incomplete, resulting in the generation of partially processed, nonamidated stable forms of the peptide (OT-Gly ${ }^{10}$, OT-Gly ${ }^{10}$-Lys ${ }^{11}$, and OT-Gly ${ }^{10}$-Lys ${ }^{11}-$ Arg $^{12}$ ). The presence of OT-Gly ${ }^{10}$-Lys ${ }^{11}$-Arg ${ }^{12}$ as a major, stable intermediate form, indicated that the in vivo pattern of endoproteolytic cleavage occurred principally at the C-terminus of the pair of basic amino acids at the tripeptide spacer sequence (Gly-Lys-Arg) in the precursor. Although both precursors were first expressed nearly simultaneously in the brain, the steady-state levels of the precursors were very different throughout fetal life. From E16-E21, the quantities of AVP precursors and peptides were 5- to 10-fold greater than those of OT, suggesting a much higher level of precursor biosynthesis in the AVP neurons. In addition to these differences in the regulation of biosynthesis and processing, AVP peptides were axonally transported to the pituitary $3 \mathrm{~d}$ earlier than OT peptides, and in far greater $(20$-fold) abundance. The early pres-

\footnotetext{
Received June 23, 1987; revised Mar. 29, 1988; accepted Apr. 19, 1988.

We wish to thank Mrs. Shirley House for excellent technical assistance, Dr. $K$. Lederis from the University of Calgary for antiserum to vasopressin and oxytocin, Dr. M. Morris from Wake Forest University for antiserum to oxytocin, and Dr. J. T. Russell from the National Institutes of Health, Bethesda, for valuable advice about radioimmunoassay and for vasopressin antiserum. We also wish to thank Dr. J. Rivier from the Clayton Foundation Laboratories for Peptide Biology at the Salk Institute and Dr. M. Karten from the National Institutes of Health. Bethesda for synthesizing and supplying C-terminally extended forms of vasopressin and oxytocin, and a special thanks to Robert Moy for doing the art work.

Correspondence should be addressed to Dr. Harold Gainer, National Institutes of Health, Building 36, Room 4D-20, Bethesda, MD 20892

a Present address: Volcani Center, POB 6, Bet-Dagan, 50-250 Israel. 0270-6474/88/113967-11\$02.00/0
}

ence and abundance of amidated AVP in the brain and pituitary suggests a trophic function for this peptide during development.

Arginine vasopressin (AVP), oxytocin (OT), and their associated neurophysins (Np-AVP and Np-OT) are synthesized principally in magnocellular neurosecretory neurons located in the paraventricular (PVN) and the supraoptic (SON) nuclei in the hypothalamus (for reviews, see Castel et al., 1984; Sofroniew, 1985). It is now well established that both peptide hormones and their Nps are first synthesized as large precursor proteins that are then transformed by a variety of posttranslational processing steps to form the biologically active hormones (reviewed in Gainer, 1983; Ivell et al., 1983; Douglas et al., 1984; Loh et al., 1984). A large number of studics on the ontogeny of the hypothalamoneurohypophysial system (HNS) have found that the AVP peptide and the neurons that synthesize this peptide appear relatively early [around embryonic day (E) 16-17] in fetal development, whereas the OT peptide is not present until about the time of birth [i.e., between E20 to postnatal day (PN) 0] (Leclerc and Pelletier, 1977; Choy and Watkins, 1979; Watkins and Choy, 1979; Boer et al., 1980a, b; Buijs et al., 1980; Khachaturian and Sladek, 1980; Krisch, 1980; Sinding et al., 1980; Sladek et al., 1980; Boer, 1987). However, from these data it was not possible to evaluate whether the delayed appearance of the OT compared with the AVP was due to a delay in gene expression of the peptide prohormones or to other cellular mechanisms. In an attempt to examine this issue, Whitnall et al. (1985) found in immunocytochemical studies, using monoclonal antibodies directed specifically against Np-OT and NpAVP and their respective prohormones (Ben-Barak et al., 1985), that both cell types were expressing their peptide prohormones (i.e., $\mathrm{Np}$ immunoreactivity) early in development (i.e., around E16-17). Given the above data, Whitnall et al. (1985) suggested that the apparent paradox of an early appearance of both prohormones in fetal development but the lack of fully processed OT (in contrast to AVP) could be explained by a differential development of posttranslational processing in these 2 related neurons. However, the antibodies used in the above study could not distinguish between prohormones and processed neurophysins, and it remained unclear whether the OT prohormone was incompletely processed or not processed at all during fetal life.

In this study, we test this hypothesis of differential processing in OT and AVP neurons during development by using quantitative radioimmunoassay (RIA) analyses that can detect the 
theoretical intermediate (partially processed) forms of both peptides as well as the precursor levels in the brain and neural lobe. Since the amino acid sequences and overall structures of the AVP and OT precursors are known from recombinant DNA studies (Land et al., 1982; 1983; Ivell et al., 1983; Ivell and Richter, 1984), it is possible to predict the theoretical intermediate forms of both peptides. We used such peptides to generate specific antibodies and RIAs that could measure the partially processed (carboxy-terminal extended) forms of AVP and OT. As a result of these studies, we report here that (1) OT and AVP or their respective prohormones are present in fetal rat brain (E15-E21) with an approximately 5- to 10-fold greater expression of AVP versus OT prohormone throughout these developmental stages, (2) posttranslational processing mechanisms are significantly delayed in OT versus AVP neurons, so that AVP is completely processed to amidated AVP as early as E16, whereas amidated OT is not detectable until E21, (3) the principal stable intermediate form of OT is OT-Gly ${ }^{10}$ Lys $^{11}$ $\mathrm{Arg}^{12}$, indicating that the endopeptidase involved in in vivo processing cleaves on the carboxyl side of the arginine, and (4) the transport of AVP to the neural lobe of the pituitary precedes that of OT by at least $3 \mathrm{~d}$. A preliminary report of some of these findings has been presented elsewhere (Altstein and Gainer, 1986).

\section{Materials and Methods}

\section{Materials}

Animals. Sprague-Dawley rats (Zivic-Miller Labs, Allison Park, PA) of various ages were used in this study: embryonic, early postnatal, and adult. These 3 groups will be referred to as E15-E21, PN0-PN21, and adult. Pregnancy was determined by the presence of a copulation plug, and the first day of gestation was the day following insemination.

Radioactive compounds. [8-Arginine] ${ }^{125} \mathrm{I}$-vasopressin $(2200 \mathrm{Ci} / \mathrm{mmol})$ and $125 \mathrm{I}-$ oxytocin $(2200 \mathrm{Ci} / \mathrm{mmol})$ were purchased from Dupont-New England Nuclear Corp. (Boston).

Hormones and analogs. 8-Arginine vasopressin and oxytocin were a gift from Ferring Pharmaceuticals (Malmo, Sweden). C-terminally extended forms of vasopressin (AVP-Gly ${ }^{10}$, AVP-G; AVP-Gly ${ }^{10}$-Lys ${ }^{11}$, AVP-GK; AVP-Gly ${ }^{10}-$ Lys $^{11}-$ Arg $^{12}$, AVP-GKR) and oxytocin (OT-Gly ${ }^{10}$, OT-G; OT-Gly ${ }^{10}$-Lys ${ }^{11}$, OT-GK; OT-GLY ${ }^{10}$-LYS ${ }^{11}$-ARG G, ${ }^{12}$, OT-GKR) were synthesized by Dr. J. Rivier from the Clayton Foundation Laboratories for Peptide Biology at the Salk Institute and were obtained from Dr. M. Karten (NICHD, Bethesda, MD).

Other chemicals and reagents. BSA (RIA grade), trypsin (TPCK treated, $N-\alpha$-p-tosyl-t-lysine chloromethyl ketone (TLCK), HEPES ( $N$-2hydroxyethyl-piperazine- $N^{\prime}-2$ ethanesulfonic acid) and Tris-(hydroxyethyl)-aminoethan were purchased from Sigma Chemical Co. (St. Louis). Carboxypeptidase B from porcine pancreas was obtained from Boehringer Mannheim Biochemicals (Indianapolis, IN). Fluorescamine was purchased from Hoffmann-La Roche Inc. (Nutley, NJ), hydrochloric acid (sequential grade), and trifluoroacetic acid (HPLC/spectro grade) from Pierce Chemical Company (Rockford, IL), methanol (HPLC grade) from Waters Associates (Milford, MA), and acetic acid (glacial) (HPLC grade) was purchased from J. T. Baker Chemical Co. (Phillipsburg, NH). All other chemicals were of analytical grade.

Columns and high-voltage electrophoresis plates. Sep-Pak $\mathrm{C}_{18}$ reversephase columns were purchased from Waters Associates and thin-layer chromatography plates (cellulose, Anacil C, $250 \mu \mathrm{m}$ ) for high-voltage electrophoresis were obtained from Analab, Inc. (North Haven, CT).

Immunological reagents. Studies on the content of brain of HNS hormones and their posttranslational processing mechanisms require antibodies that can recognize and distinguish between the various forms of cleaved hormones, i.e., fully (amidated) and partially processed (Cterminally extended) forms (see Fig. 1 for theoretical peptide intermediates and final hormones). After screening various AVP and OT antisera, the following antibodies were chosen for this study: anti-vasopressin (AVP-VA4) and anti-oxytocin (OT-VA17), which were raised and characterized in our laboratory (Altstein et al., 1988). Anti-vasopressin (AVP-LD) (Moore et al., 1977) and anti-oxytocin (OT-LD) were obtained from Dr. K. Lederis from the Department of Pharmacology and Therapeutics, Faculty of Medicine, University of Calgary. Antioxytocin (OT-MM) (Morris et al., 1980) was obtained from Dr. M. Morris from the Department of Physiology and Pharmacology, Bowman Gray School of Medicine, Wake Forest University, and anti-vasopressin (AVP-JR1) was obtained from Dr. J. T. Russell from the Laboratory of Neurochemistry and Neuroimmunology, National Institutes of Health. The characteristics of these antisera are shown in Tables 1 and 2.

\section{Immunological analyses}

Radioimmunoassay. Determination of immunoreactive material by liquid-phase RIA was performed as follows. Reaction mixtures containing $100 \mu \mathrm{I}^{125} \mathrm{I}$-tracer (approximately $7000 \mathrm{cpm}$ of AVP or OT), diluted in Kreb's Ringer (125 mM NaCl, 4.5 mM KCl, $1.5 \mathrm{mM} \mathrm{MgSO}_{4}, 2.0 \mathrm{~mm}$ $\mathrm{CaCl}_{2}, 2 \mathrm{~mm}$ HEPES, and $\left.1.5 \mathrm{mg} / \mathrm{ml} \mathrm{BSA}, \mathrm{pH} 7.4\right), 100 \mu \mathrm{l}$ standard $(1.95-1000 \mathrm{pg} /$ tube AVP or OT) or unknown sample, and $400 \mu \mathrm{l}$ of antisera (at a dilution providing $30-50 \%$ binding), all in a total volume of $600 \mu \mathrm{l} 0.1 \mathrm{M}$ Na phosphate buffer containing $1.5 \mathrm{mg} / \mathrm{ml} \mathrm{BSA}, \mathrm{pH}$ 7.4 (RIA buffer), were incubated, under equilibrium conditions, for 48 $\mathrm{hr}$ at $4^{\circ} \mathrm{C}$. Incubation was terminated by the addition of $1.26 \mathrm{ml}$ icccold ethanol (68\% final concentration), and bound complex was separated from unbound tracer by centrifugation at $1500 \times g$ for $30 \mathrm{~min}$ at $4^{\circ} \mathrm{C}$. The supernatant was discarded, and the pellet (bound fraction) was counted for radioactivity. Nonspecific binding (3-5\%) was determined in the absence of antibody and was subtracted from every tube. The amount of immunoreactive material was determined using a standard curve of synthetic AVP and OT (the lower limit of assay sensitivity for both peptides was $3 \mathrm{pg} /$ tube). RIA results were calculated using a logit transformation of the raw data [Fortran IV program (RIAPROG) developed at the National Institutes of Health by V. B. Faden and D. Rodbard]

Cross-reactivity analysis. Antisera were characterized by analyzing their cross-reactivities with the peptide intermediates and final hormone peptides that are assumed to result from the in vivo processing of the prohormones (see Fig. 1 for theoretical intermediates). Cross-reactivity analysis was performed by liquid-phase RIA (see above), except that the unknown samples were substituted with serial dilutions of known hormone analogs. Samples were prepared in RIA buffer and incubated with specific antisera and iodinated tracers as described above, and cross-reactivity was determined by comparing the potency of fully processed (amidated) and partially processed (C-terminally extended) forms of AVP and OT to displace iodinated AVP or OT from a given antibody.

The results of these studies (Tables 1 and 2) demonstrated that the AVP and OT-specific antibodies could be divided into those that only recognized the C-terminally amidated forms (AVP-JR1 and OT-MM) and those that recognized both forms, i.e., C-terminally amidated and C-terminally extended nonamidated peptides (AVP-LD, AVP-VA4, OTLD, and OT-VA17). For the AVP-specific antibodies, AVP-JR1 was found to be directed mainly towards the C-terminal region of AVP, whereas AVP-LD and AVP-VA4 were found to be directed mainly towards the $\mathrm{N}$-terminal region of the hormone since they cross-reacted with C-terminally extended forms of AVP and truncated AVP (desGly$\mathrm{NH}_{2}$-AVP) (Table 1). Among the OT-specific antibodies OT-MM was found to be directed mainly towards the $C$-terminal region of $O T$, whereas OT-LD and OT-VA17 were found to be directed mainly towards the $\mathrm{N}$-terminal region of the hormone (Table 2). All AVP and OT antibodies were found to be specific for their homologous hormones and no crossreactivity was detected with OT of AVP and their analogs, respectively.

\section{Experimental procedures}

Tissue dissections. On the day of the experiment the mothers were anesthetized and the uterus was immediately dissected. The fetuses were removed and decapitated, and the heads were kept on ice during the time of dissection. Brains and pituitaries containing the neural lobe (obtained separately only after E18) were removed and quickly frozen on glass slides placed on dry ice. Twelve to fifteen brains and pituitaries were used at each embryonic stage, and 8 brains or pituitaries were used at each postnatal stage. For the embryonic stages, the entire brain was homogenized. However, postnatal brains were further dissected to remove the hypothalamus and median eminence, which were homogenized together for analysis. Over $99 \%$ of the AVP and OT in the rat CNS is found in these dissected brain areas postnatally (Boer et al., 1980c; Castel et al., 1984; Sofroniew, 1985; Boer, 1987).

Tissue extraction. The above tissues were transferred to precooled 
Table 1. Cross-reactivity of anti-AVP antibodies with AVP, OT, and their analogs

\begin{tabular}{|c|c|c|c|}
\hline \multirow[b]{2}{*}{ Peptide } & \multicolumn{3}{|c|}{ Relative displacement factor $(\%)^{a}$} \\
\hline & $\begin{array}{l}\text { AVP-JR1 } \\
(1: 45,000)\end{array}$ & $\begin{array}{l}\text { AVP-LD } \\
(1: 100,000)\end{array}$ & $\begin{array}{l}\text { AVP-VA4 } \\
(1: 16,000)\end{array}$ \\
\hline AVP & 100 & 100 & 100 \\
\hline AVP-Gly ${ }^{10}$ & $<0.44$ & 34 & 46 \\
\hline AVP-Gly ${ }^{10}-$ Lys $^{11}$ & $<0.44$ & 30 & 76 \\
\hline AVP-Gly-10 Lys-" $1-A r g{ }^{12}$ & $<0.44$ & 30 & 51 \\
\hline desGly-NH - AVP & $<0.44$ & 46 & 71 \\
\hline LVP & 16 & 5 & 8 \\
\hline AVT & 241 & $<1.5$ & $<2$ \\
\hline OT & 0.02 & $<0.02$ & $<2$ \\
\hline OT-Gly ${ }^{10}$ & n.t & $<0.02$ & n.t. \\
\hline OT-Gly-10-Lys ${ }^{11}$ & n.t & $<0.02$ & n.t \\
\hline OT-Gly' ${ }^{10}-$ Lys $^{11}-$ Arg $^{12}$ & n.t. & $<0.02$ & n.t. \\
\hline
\end{tabular}

a Relative displacement factor represents the ratio (in \%) of AVP. concentration required to displace $50 \%$ of ${ }^{125}$ I-AVP from an antibody to the concentration required to get the same degree of displacement with any other hormone or analog. Cross-reactivity was determined from displacement curves as described in Methods using ${ }^{125}$ I-AVP as a tracer and 6-10 dilutions of hormone or analog, in duplicates, within the following range of concentrations: AVP-JR1, 3.90 $\mathrm{pg} /$ tube-20 ng/tube; AVP-LD, $19.5 \mathrm{pg} /$ tube-100 ng/tube; AVP-VA4, $1.95 \mathrm{pg} /$ tube-1 ng/tube. Numbers in parentheses indicate final antibody dilutions. LVP, Lys ${ }^{8}$-vasopressin; AVT, vasotocin; n.t., not tested.

glass-glass homogenizers containing $10 \mathrm{ml}$ (per 10 brains) or $1 \mathrm{ml}$ (per 10 pituitaries) of $0.1 \mathrm{~N}$ hydrochloric acid $(\mathrm{HCl})$ and homogenized manually. Samples were centrifuged at $12,100 \times g$ for $15 \mathrm{~min}$ at $4^{\circ} \mathrm{C}$, and the supernatant (S1) was used for the analysis of fully processed forms of AVP and OT by means of RIA as described above. The remaining sample was treated with trichloroacetic acid (TCA, $10 \%$ final concentration) for $2 \mathrm{hr}$ on ice and spun at $10,000 \times g$ for $10 \mathrm{~min}$ at $4^{\circ} \mathrm{C}$. The resulting supernatant (S2) was ether-washed, lyophilized, resuspended in half the original volume $0.1 \mathrm{M}$ Na phosphate buffer containing 1.5 $\mathrm{mg} / \mathrm{ml} \mathrm{BSA}$, pH 7.4 (RIA buffer) and assayed for fully processed and partially processed (C-terminally extended) forms of AVP and OT by means of RIA and high-voltage electrophoresis (HVE) chromatography (see below). The pellet (P2) was ether-washed, air-dried, dissolved in either $2.0 \mathrm{ml}$ (brain) or $0.14 \mathrm{ml}$ (pituitary) $10 \mathrm{~mm}$ Tris- $\mathrm{HCl}$, pH 8.0 (trypsinization buffer), and incubated in the presence or absence of trypsin $(10 \mu \mathrm{g} / \mathrm{ml})$ for $2 \mathrm{hr}$ at $37^{\circ} \mathrm{C}$. Incubation was terminated by TLCK $(0.025 \mathrm{mg} / \mathrm{ml})$, and samples were then assayed for tryptic cleavage products by means of RIA as described above.
Determination of peptide recoveries in extracts. The validity of the extraction procedure was evaluated by determining the recovery of labeled or unlabeled synthetic AVP and OT. Iodinated AVP or OT was added to $4 \mathrm{ml}$ of $0.1 \mathrm{~N} \mathrm{HCl}$ containing 4 hypothalami and was extracted as described above. Radioactivity was monitored in S1 and S2 supernatants, and recovery was calculated to be 70 and $60 \%$ for $\mathrm{S} 1$ and $\mathrm{S} 2$, respectively, for both hormones. Recovery of peptide-IR in S2 after TCA precipitation was also determined using unlabeled hormones. AVP and OT $(750 \mathrm{ng} / \mathrm{ml})$ were subjected to TCA precipitation as described above in the presence of $150 \mu \mathrm{g} / \mathrm{ml}$ BSA. Samples were spun and etherwashed, and the $\mathrm{S} 2$ supernatant was tested for hormone content using RIA standard curves as described in the cross-reactivity section. Recovery in S2 was determined using AVP-JR1 (1:45,000) and OT-MM $(1: 100,000)$ antisera and was calculated from the ratio (in \%) of AVP or OT concentration required to displace $50 \%$ of ${ }^{125} \mathrm{I}-\mathrm{AVP}$ or ${ }^{125} \mathrm{I}-\mathrm{OT}$, respectively, before and after TCA precipitation. Recovery was found to be 64 and $54 \%$ for AVP and OT, respectively.

High-voltage electrophoresis. TCA-treated supernatants from 10 brains

Table 2. Cross-reactivity of anti-OT antibodies with OT, AVP, and their analogs

\begin{tabular}{|c|c|c|c|}
\hline \multirow[b]{2}{*}{ Peptide } & \multicolumn{3}{|c|}{ Relative displacement factor $(\%)^{a}$} \\
\hline & $\begin{array}{l}\text { OT-MM } \\
(1: 100,000)\end{array}$ & $\begin{array}{l}\text { OT-LD } \\
(1: 60,000)\end{array}$ & $\begin{array}{l}\text { OT-VA17 } \\
(1: 60,000)\end{array}$ \\
\hline OT & 100 & 100 & 100 \\
\hline OT-Gly ${ }^{10}$ & 0.01 & 81 & 87 \\
\hline OT-Gly ${ }^{10}-$ Lys $^{11}$ & 0.01 & 54 & 35 \\
\hline OT-Gly-10-Lys-" ${ }^{11}$-Arg ${ }^{12}$ & $<0.007$ & 45 & 78 \\
\hline AVP & 0.01 & 35 & $<2$ \\
\hline LVT & 0.09 & $<0.03$ & $<2$ \\
\hline AVP & 0.04 & $<0.03$ & $<2$ \\
\hline AVP-Gly ${ }^{10}$ & n.t & $<0.6$ & n.t. \\
\hline AVP-Gly-10-Lys" & n.t & $<0.03$ & n.t \\
\hline AVP-Gly ${ }^{10}-$ Lys $^{11}-$ Arg $^{12}$ & n.t. & $<0.03$ & $<2$ \\
\hline desGly-NH ${ }_{2}$-AVP & n.t. & $<0.03$ & $<2$ \\
\hline
\end{tabular}

${ }^{a}$ Relative displacement factor represents the ratio (in \%) of OT concentration required to displace $50 \%$ of ${ }^{25}$ I-AVP from an antibody to the concentration required to get the same degree of displacement with any other hormone or analog. Cross-reactivity tested using ${ }^{125} \mathrm{I}$-OT as a tracer and 6-10 dilutions of hormone or analog, in duplicates, within the following range of concentrations: OT-MM, $1.95 \mathrm{pg} /$ tube-1 $\mu \mathrm{g} /$ tube; OT-LD, $19.5 \mathrm{pg} /$ tube-100 ng/tube; OT-AV17, 1.95 $\mathrm{pg} /$ tube-1 $\mathrm{ng} /$ tube. All other details are as described in the legend to Table 1. 
oxyTOCIN

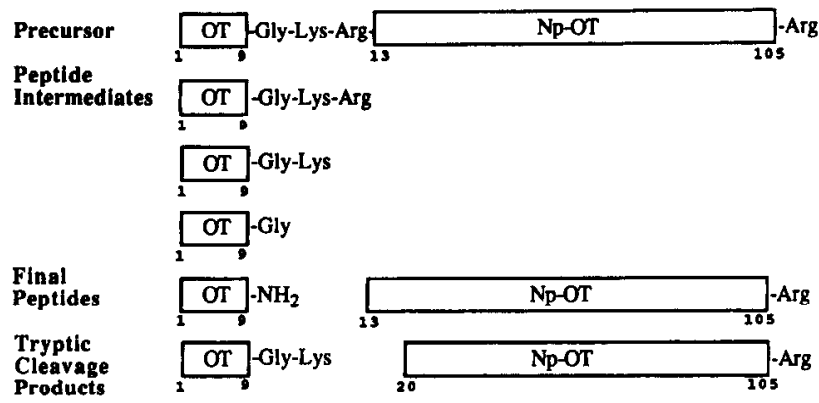

VASOPRESSIN

Figure 1. Structures of oxytocin and vasopressin precursors (prohormoncs), the fully processed (final) peptides found in vivo, and theoretical peptide hormone intermediates resulting from precursor processing. Also shown are the products of in vitro incubation of the precursors with trypsin. Abbreviations: $O T$, oxytocin; $A V P$, vasopressin; $N p$ $O T$, oxytocin-associated neurophysin; $N p-A V P$, vasopressin-associated neurophysin; GP, glycopeptide; $A V P 1-8$, desglycinamide-AVP.

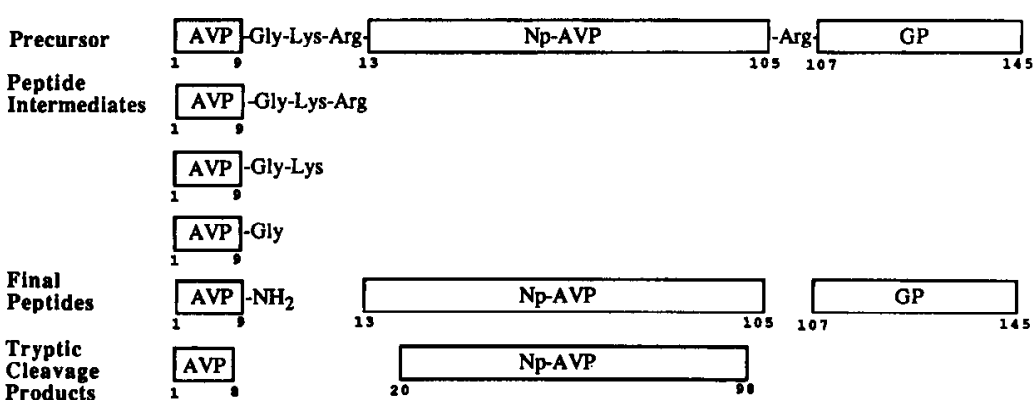

and pituitaries (S2) were prepared as described above and used for HVE analysis. Prior to the HVE, extracts were partially purified on a SepPak $\mathrm{C}_{18}$ reverse-phase column. Samples were applied onto the column and washed with $5 \mathrm{ml}$ of $0.1 \%$ trifluoracetic acid (TFA) to remove nonpeptide contaminants. The peptides were eluted from the Sep-Pak by two $1 \mathrm{ml}$ washes of $80 \%$ methanol, containing $0.1 \%$ TFA. The eluate was dried, reconstituted in $20 \mu \mathrm{l} 0.01 \mathrm{~N} \mathrm{HCl}$, and analyzed by $\mathrm{HVE}$ on cellulose plates in a pH 2 system (formic acid/acetic acid/water, 20:80: 900 ). The electrophoresis was carried out at $900 \mathrm{~V}$, and front migration (15.5 $\mathrm{cm}$ from origin) was determined by a methyl green marker. The plate was then cut in $1 \mathrm{~cm}$ fractions beginning $1 \mathrm{~cm}$ below the origin, peptides were extracted from the cellulose with $500 \mu \mathrm{l} 0.1 \mathrm{~N} \mathrm{HCl}$, and all fractions were assayed for immunoreactive material by means of RIA as described below. Markers (AVP, OT, and their C-terminally extended forms) were run on adjacent lanes and visualized by fluorescamine (Mandez and Lai, 1973) and by RIA. Sample recovery was evaluated using synthetic AVP and OT, and was $>98 \%$ for Sep-Pak columns and $20 \%$ for HVE.

\section{Results}

Studies on the oxytocin and vasopressin genes (Land et al., 1982, 1983; Ivell et al., 1983; Ivell and Richter, 1984) and the biosynthesis of their prohormones (reviewed in Gainer, 1983) have clarified the structural forms of the prohormone precursors. Based on our current understanding of peptide precursor processing (Douglas et al., 1984; Loh et al., 1984; Gainer et al., 1985), it is possible to deduce the theoretical intermediate peptide forms produced by processing the precursors to the final peptide forms (Fig. 1). In the sections below we systematically evaluate the presence of the precursors and intermediatc forms in the rat brain during development, using specific antibodies in RIA which are particularly appropriate for such an analysis (see Tables 1 and 2, and Methods).

\section{Quantitative analyses of AVP and OT peptides during development}

Quantitative analyses of fully processed (amidated) forms of AVP and OT were performed using antibodies (AVP-JR1 and
OT-MM) that recognize only the amidated forms of the hormone in RIAs on brain or pituitary extracts before TCA precipitation ( $\mathrm{S} 1$, see Methods). These data are illustrated in Figure 2 , scparatcly for the brain and pituitary. The data are similar to previous analyses of these peptides during ontogeny, which have reported a delayed appearance of OT versus AVP peptides (see introduction). AVP was first detected by RIA on E17 in the brain, whereas OT could only be first detected on E21 in the pituitary. AVP, on the other hand, was measurable in the pituitary on E18 (the first embryonic day that the pituitary could be isolated as a distinct entity). In view of the immunocytochemical evidence (Whitnall et al., 1985) that the precursor for OT was expressed significantly earlier than E21, we next examined whether unamidated intermediate forms of OT were present at these early stages.

Quantitative RIA analysis of all forms of cleaved peptides (fully and partially processed) was performed using antibodies (anti-AVP-LD and anti OT-LD) that recognize both amidated and unamidated (C-terminally extended) peptides. The antibodies used in these analyses were found to react with all forms of the AVP or OT peptides, as well as, to some extent, the peptide hormone sequences contained within the precursors (M. Altstein, unpublished observations). Therefore, separation of cleaved hormones from precursors was performed by TCA precipitation of the brain and pituitary extracts, and the resultant supernatants (S2, see Methods) were used for the determination of the fully and partially processed (cleaved) peptides in brain and neural lobe. The data, illustrated in Figure 3, show that cleaved forms of OT are detectable in the rat brain as early as E18 and continue to increase throughout fetal development. Interestingly, however, the first detection in the pituitary was at E21, suggesting that primarily amidated forms of OT were being transported to the neural lobe at this time (compare Figs. 1 and 2). Since the thresholds of detection in all the assays were comparable (i.e., $3 \mathrm{pg} /$ tube, see Methods), the finding of signif- 


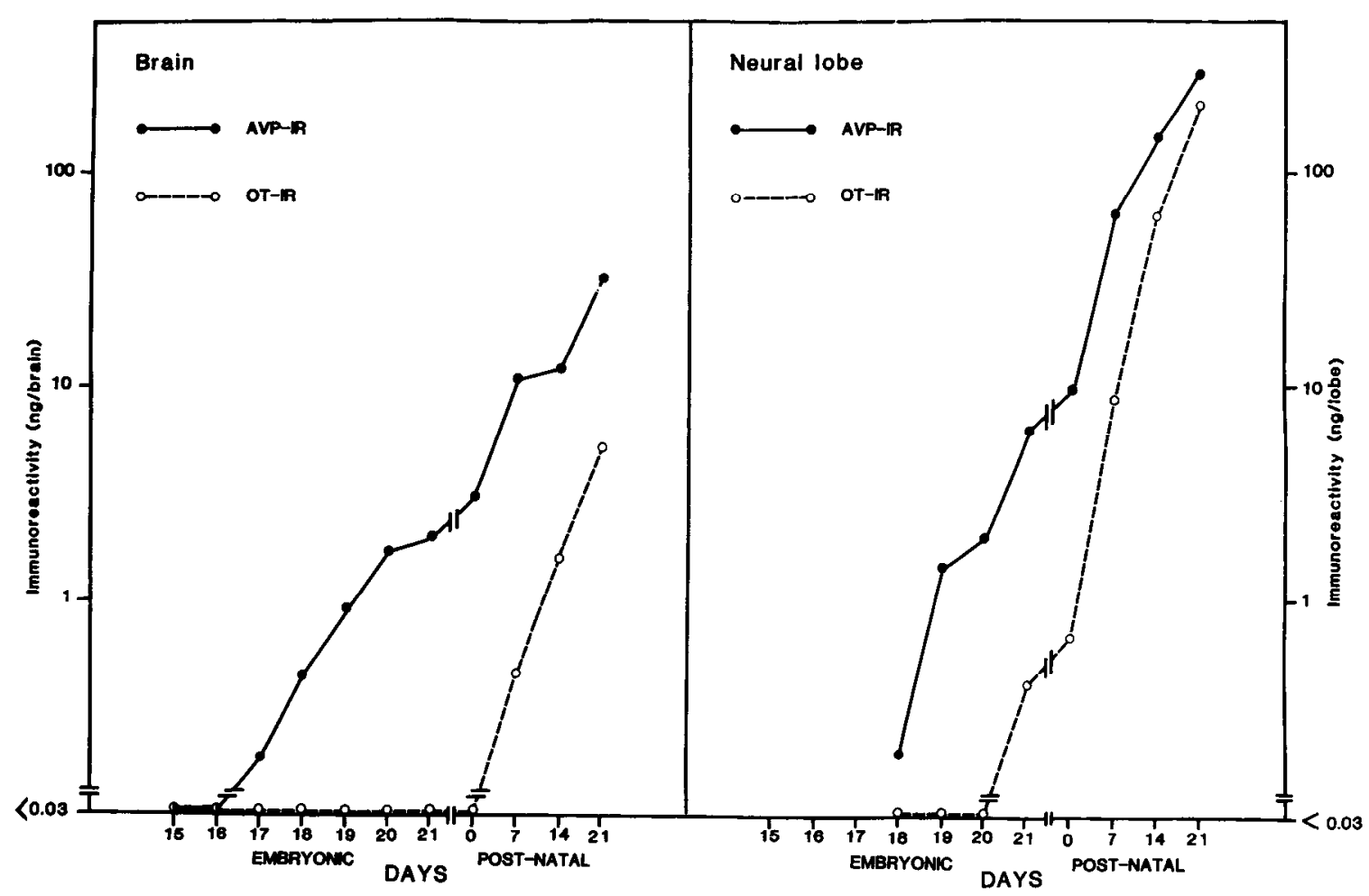

Figure 2. Content of fully processed (amidated) AVP and OT in brain (left) and neural lobe of the pituitary (right) found at different stages of development. Hormone content was determined by RIA using antibodies (AVP-JR1, 1:45,000, and OT-MM, 1:100,000) that recognize the fully processed amidated hormones (see Tables 1 and 2), and either brain or neural lobe of the pituitary extracts before TCA precipitation (S1 in Methods). Each point represents the mean of 3-5 serial dilutions in duplicates (ranging from 1:2 to 1:32 for brain extracts and 1:20 to 1:160 for pituitary extracts) with a variation of less than $8 \%$. Values less than $0.03 \mathrm{ng} /$ brain or neural lobe were below the detection limit of the assays. Note that while AVP is detectable on E17 in the brain and on E18 in the pituitary, OT is not detectable until E21 (in the neural lobe).

icant OT immunoreactivity in the brain with the OT-LD antibody (Fig. 3) but not the amide-requiring OT-MM antibody (Fig. 2) strongly suggested that primarily unamidated OT peptide intermediates were present in the brain during fetal life.

The differences in the immunoreactivities obtained with these 2 classes of antibodies allowed for comparisons of the content of partially and completely processed forms of AVP and OT. Figure 4 (left panel) shows that no extended forms of AVP (AVP$X-I R$ ) could be detected in the brain at any developmental stage and that only the fully processed amidated hormone was significantly present. OT extended forms (OT-X-IR), however, were found in the brain beginning at E18 and throughout development, indicating that the OT precursor is synthesized during embryonic stages but is not fully processed to form amidated OT (Fig. 4, right panel). However, by PN7 both forms of OT were substantially found in the brain, and the ratio of amidated to unamidated hormone increased from 0.51 at PN7 to 0.98 at PN21 (Fig. 4, right panel). Analysis of neural lobe extracts showed that the first detection of AVP (on E18) and OT (E21) consisted essentially of completely processed (amidated) forms (see also Tables 3 and 4). Although partially processed forms of OT immunoreactivity could be detected at all embryonic stages, the overall level of the OT immunoreactivity was relatively low compared with AVP levels during fetal life (Tables 3, 4).

\section{Characterization of the intermediate forms of OT}

Since the antibodies that recognized the partially processed peptides were unable to distinguish between the different C-ter-
Table 3. Quantitative analysis of immunoreactive AVP in the developing rat brain and pituitary

\begin{tabular}{|c|c|c|c|c|c|c|}
\hline \multirow[b]{2}{*}{ Day } & \multicolumn{3}{|c|}{ ng AVP/Brain ${ }^{a}$} & \multicolumn{2}{|c|}{ ng AVP/pituitary $b$} & \multirow[b]{2}{*}{$\begin{array}{l}\text { Total } \\
\text { ng AVP }\end{array}$} \\
\hline & $\begin{array}{l}\text { Pre- } \\
\text { cursor }\end{array}$ & $\begin{array}{l}\text { Cleaved } \\
\text { peptide }\end{array}$ & $\begin{array}{l}\% \\
\text { Ami- } \\
\text { dated }\end{array}$ & $\begin{array}{l}\text { Cleaved } \\
\text { peptide }\end{array}$ & $\begin{array}{l}\% \\
\text { Ami- } \\
\text { dated }^{c}\end{array}$ & \\
\hline \multicolumn{7}{|c|}{ Embryonic } \\
\hline 15 & 0.05 & 0 & - & - & - & 0.05 \\
\hline 16 & 0.08 & 0.04 & 100 & - & - & 0.12 \\
\hline 17 & 0.12 & 0.28 & 96 & - & - & 0.40 \\
\hline 18 & 0.24 & 0.36 & 100 & 0.20 & 95 & 0.80 \\
\hline 19 & 0.54 & 0.76 & 100 & 1.23 & 100 & 2.53 \\
\hline 20 & 0.68 & 1.49 & 100 & 2.15 & 89 & 4.32 \\
\hline 21 & 0.49 & 1.63 & 100 & 7.71 & 79 & 9.83 \\
\hline \multicolumn{7}{|c|}{ Postnatal } \\
\hline 0 & 0.99 & 1.59 & 100 & 11.33 & 83 & 13.91 \\
\hline 7 & 0.31 & 3.80 & 100 & 61.97 & 100 & 66.08 \\
\hline 14 & 0.37 & 10.48 & 100 & 137.48 & 100 & 148.33 \\
\hline 21 & 1.43 & 25.88 & 100 & 298.52 & 94 & 325.83 \\
\hline 40 & 2.33 & 95.13 & 85 & 1128.46 & 80 & 1225.92 \\
\hline
\end{tabular}

Data based on RIA measurements of AVP-IR in TCA-soluble (amidated and unamidated cleaved products) and trypsin-treated TCA-precipitable samples as described in Materials and Methods. Detection limit was $0.03 \mathrm{ng} / \mathrm{brain}$ or pituitary.

${ }^{a}$ In embryonic stages whole brains were taken for assay, and in postnatal stages only whole hypothalamus and median eminence were assayed.

b Pituitaries were dissected starting on E18. No precursor containing AVP was detected in the pituitary at any stage.

' Represents the percentage of cleaved peptides found in amidated form. 


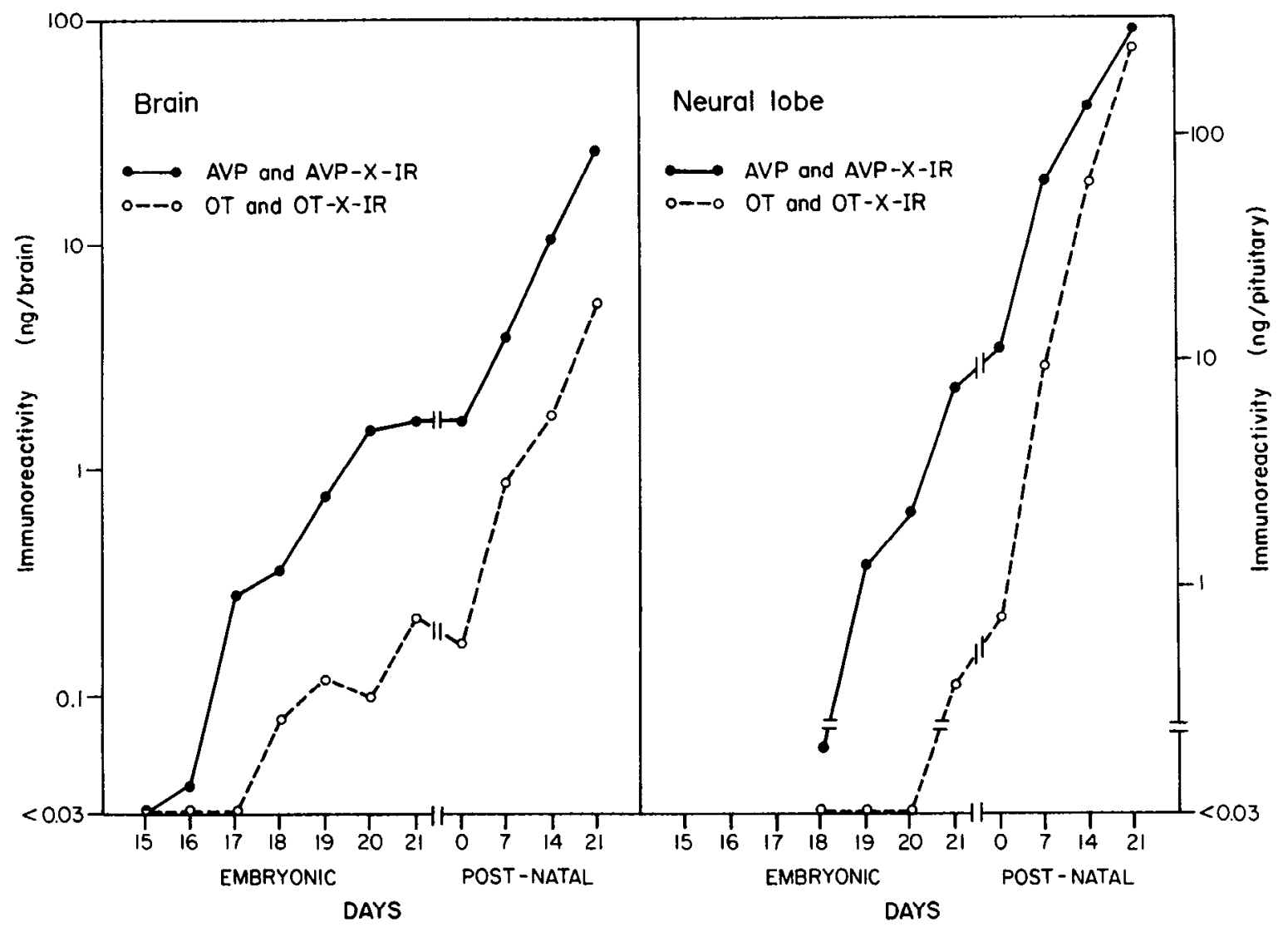

Figure 3. Content of total cleaved AVP and OT peptides [i.e., both fully processed (AVP) and partially processed forms (AVP-X)] in brain $(l e f t)$ and neural lobe (right) extracts at various embryonic and postnatal stages. Hormone content was determined by RIA using antibodies (AVP. LD, 1:100,000, and OT-LD, 1:60,000) that recognize both amidated (fully processed) and C-terminally extended (partially processed) forms of the hormone (see Tables 1 and 2), and either brain or neural lobe supernatants after TCA precipitation (S2 in Methods). Values were corrected for recovery after TCA precipitation (64 and 54\% recovery for AVP and OT, respectively). Each point represents the mean of 3-5 serial dilutions in duplicates (ranging from 1:2 to 1:32 for brain extracts and 1:40 to 1:640 for neural lobe extracts) with a variation of less than 6\%. Values less than $0.03 \mathrm{ng} /$ brain or neural lobe were below the detection limits of the assays. Note that in contrast to the data in Figure 2 , these data indicate that OT is present at early embryonic stages (E18) but in an unamidated form.

Table 4. Quantitative analysis of immunoreactive OT in the developing rat brain and pituitary

\begin{tabular}{|c|c|c|c|c|c|c|}
\hline \multirow[b]{2}{*}{ Day } & \multicolumn{3}{|c|}{ ng OT/Brain } & \multicolumn{2}{|c|}{ ng OT/pituitary } & \multirow[b]{2}{*}{$\begin{array}{l}\text { Total } \\
\text { ng OT }\end{array}$} \\
\hline & $\begin{array}{l}\text { Pre- } \\
\text { cursor }\end{array}$ & $\begin{array}{l}\text { Cleaved } \\
\text { peptide }\end{array}$ & $\begin{array}{l}\% \\
\text { Ami- } \\
\text { dated) }\end{array}$ & $\begin{array}{l}\text { Cleaved } \\
\text { peptide }\end{array}$ & $\begin{array}{l}\% \\
\text { Ami- } \\
\text { dated }\end{array}$ & \\
\hline \multicolumn{7}{|c|}{ Embryonic } \\
\hline 15 & 0 & 0 & - & - & - & 0 \\
\hline 16 & 0 & 0 & - & - & - & 0 \\
\hline 17 & 0.04 & 0 & - & - & - & 0.04 \\
\hline 18 & 0.11 & 0.08 & 0 & 0 & - & 0.19 \\
\hline 19 & 0.18 & 0.12 & 0 & 0 & - & 0.30 \\
\hline 20 & 0.19 & 0.10 & 0 & 0 & - & 0.29 \\
\hline 21 & 0.41 & 0.22 & 0 & 0.37 & 100 & 1.00 \\
\hline \multicolumn{7}{|c|}{ Postnatal } \\
\hline 0 & 0.33 & 0.17 & 0 & 0.74 & 89 & 1.24 \\
\hline 7 & 0.37 & 0.89 & 51 & 9.67 & 89 & 10.93 \\
\hline 14 & 0.48 & 1.75 & 90 & 61.89 & 99 & 64.12 \\
\hline 21 & 2.33 & 5.23 & 98 & 245.69 & 85 & 253.25 \\
\hline 40 & 2.36 & 38.42 & 82 & 1130.13 & 88 & 1170.91 \\
\hline
\end{tabular}

Data based on RIA measurements of OT-IR in TCA-soluble (cleaved products) and trypsin-treated TCA-precipitable samples as described in Material and Methods and in the legend to Table 3. No precursor containing OT was detected in the pituitary at any stage. minally extended forms, further characterization of these forms was performed by a combination of RIA with HVE. Analysis of PN14 brain and neural lobe extracts for AVP-like immunoreactivity with both sets of antibodies, after HVE fractionation, revealed only one peak of immunoreactivity above baseline, and this peak comigrated with amidated AVP (Fig. 5). These studies confirmed the absence of partially processed forms of AVP in both the brain and the neural lobe (Fig. 5).

A similar analysis for OT-like immunoreactivity is shown in Figure 6. The data indicate that both amidated and C-terminally extended forms of the hormone are present in the brain at PN7PN21 (Fig. 6, left panel), and that all 3 possible intermediate forms resulting from OT processing (i.e., OT-Gly, OT-Gly-Lys, and OT-Gly-Lys-Arg; see Fig. 1) were present. In contrast to the brain, the neural lobe contained only one peak of immunoreactivity, and this comigrated with amidated OT, confirming the paucity of partially processed forms of OT in this region (Fig. 6, right panel). Further validation of the presence of OTGly-Lys and OT-Gly-Lys-Arg in the brain was obtained by analyzing the susceptibility of these forms to carboxypeptidase $\mathrm{B}$ (CP-B) cleavage. CP-B is an exopeptidase that removes basic amino acids (Lys and Arg) from the carboxyl terminus of peptides and proteins, and hence, treatment of the C-terminally extended OT with CP-B should result in disappearance of OT- 


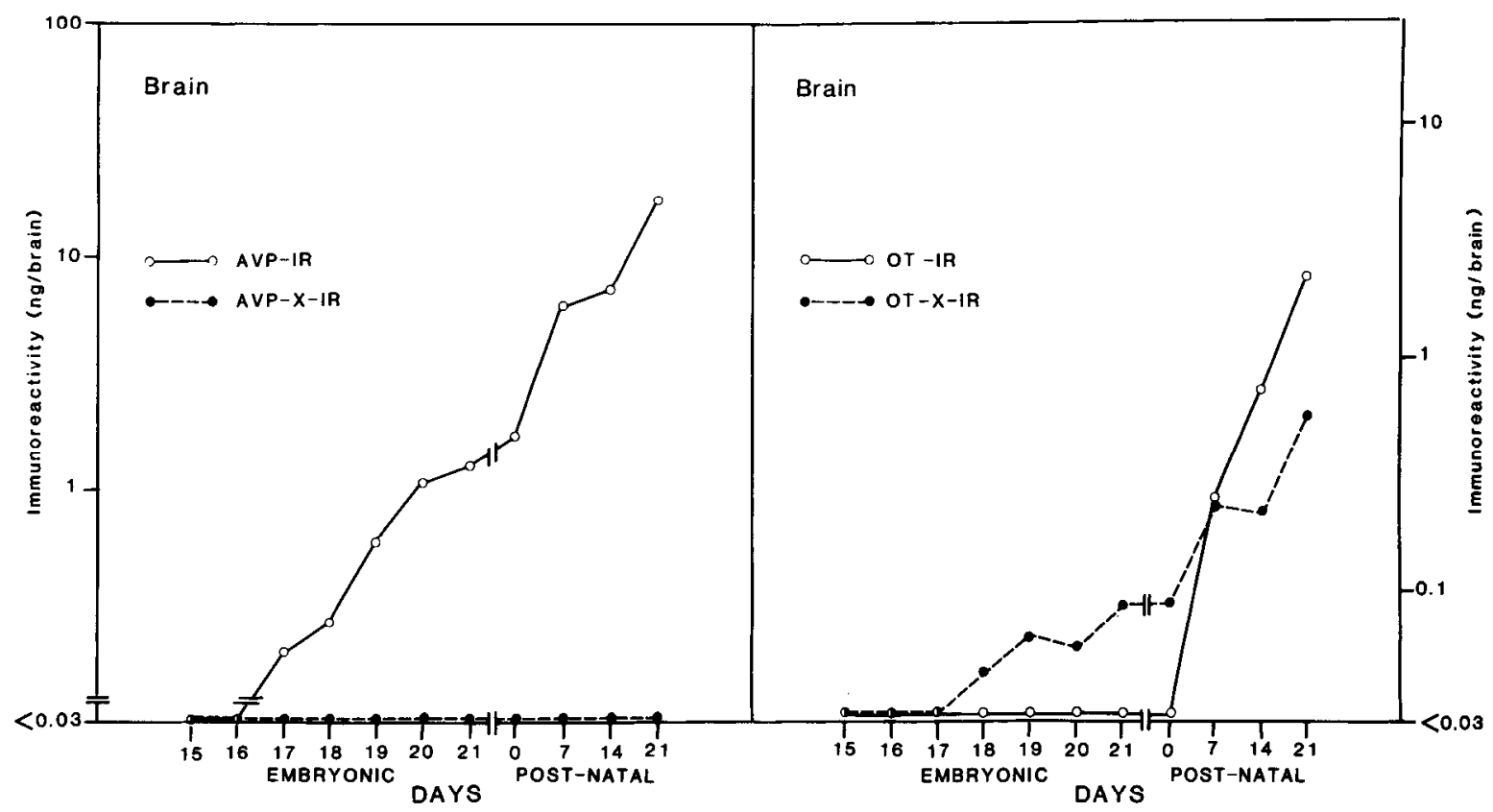

Figure 4. Comparison of content of intermediate forms (AVP-X-IR, OT-X-IR) and amidated forms (AVP-IR, OT-IR) of the peptides in brain extracts at various embryonic and postnatal stages. Content of amidated AVP and OT was determined using AVP-JR1 (1:45,000) and OT-MM $(1: 100,000)$ antisera, respectively, and the content of partially processed hormones (AVP-X and OT-X) was calculated from the differences between the immunoreactivities determined using AVP-LD and AVP-JR1 antibodies, and OT-LD and OT-MM antibodies, respectively. Experimental details are as described in the legend to Figure 3 and Methods. Note that while AVP in the brain is virtually completely processed during fetal life, $O T$ in the brain remains unamidated until after birth.

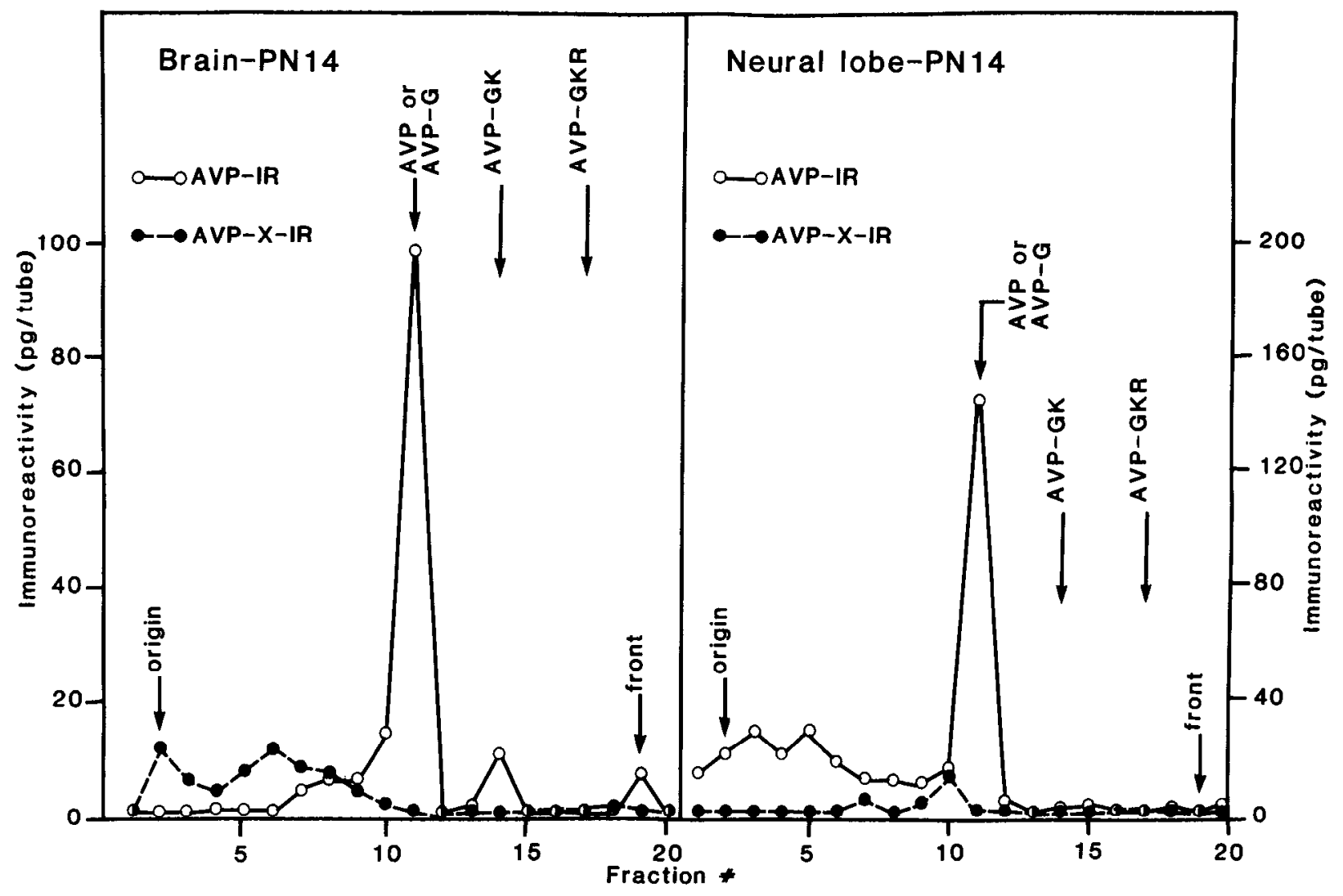

Figure 5. High-voltage electrophoresis (HVE) analysis of brain and neural lobe extracts (postnatal day 14) analyzed for fully and partially processed forms of AVP. Brain $(0.4 \mathrm{ml})$ and neural lobe $(10 \mu \mathrm{l})$ supernatants $(\mathrm{S} 2$ in Methods) were passed through a Sep-Pak column, eluted, dried, resuspended in $20 \mu 10.01 \mathrm{~N} \mathrm{HCl}$, and applied on a HVE plate for electrophoresis as described in Methods. At the end of the run, $50 \mu \mathrm{l}$ cellulose $\mathrm{HCl}$ extracts were analyzed for AVP or AVP-X immunoreactivity. AVP immunoreactivity $(0-0)$ was determined using AVP-JR1 antiserum $(1: 45,000)$, and AVP-X immunoreactivity $\left(\mathrm{O}_{--}-0\right)$ was calculated from the difference between the immunoreactivities of the AVP-VA4 $(1: 16,000)$ and AVP-JR1. Electrophoretic positions of standards (depicted by arrows) were visualized by fluorescamine and also measured by means of RIA as described in Methods. Abbreviations: $A V P-G, \mathrm{AVP}$-glycine; $A V P$ - $G K$, AVP-glycine-lysine; $A V P$-GKR, AVP-glycine-lysine-arginine (see Fig. 1). 


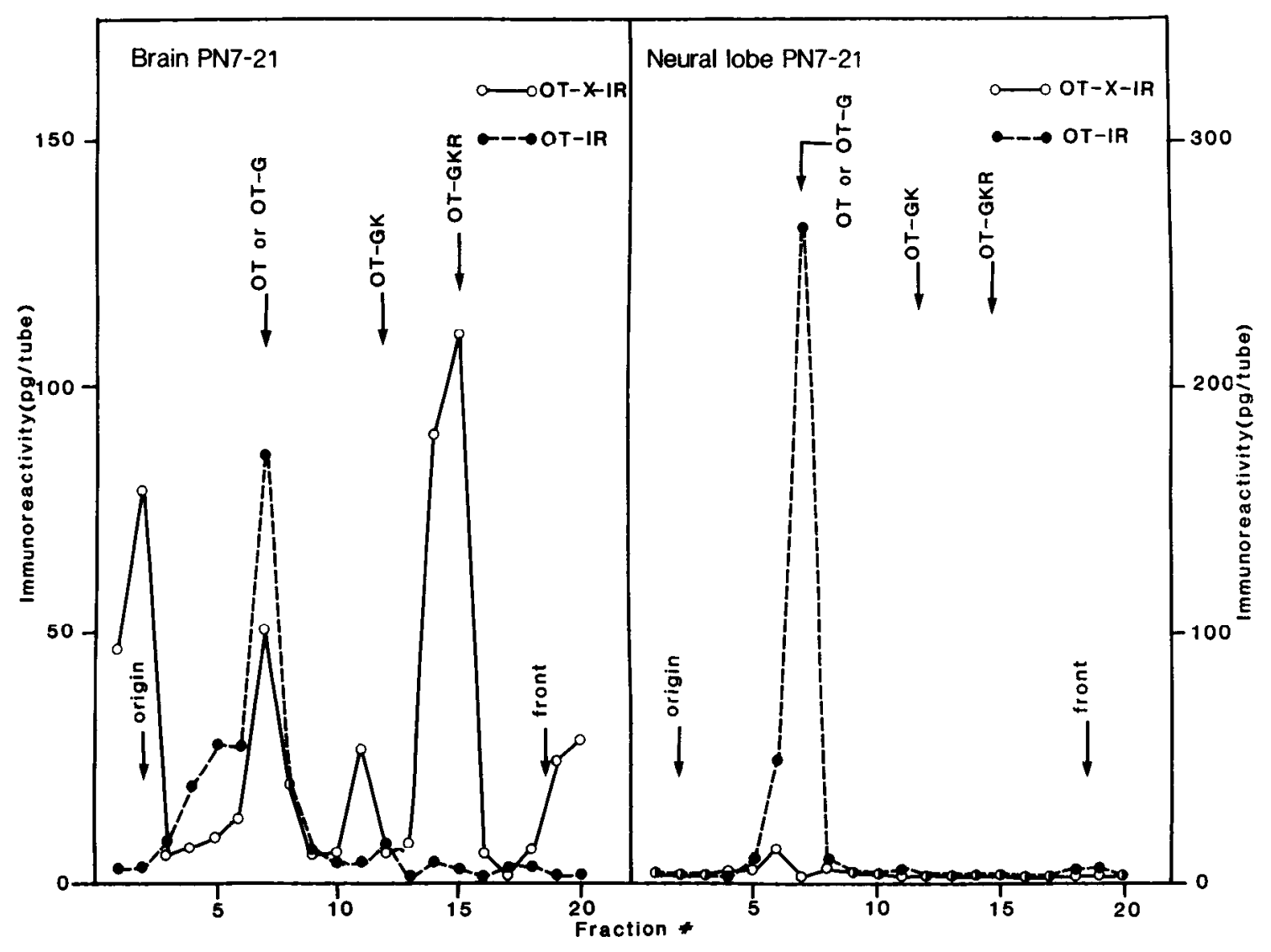

Figure 6. HVE of brain and neural lobe extracts (postnatal days 7-21) analyzed for fully and partially processed forms of OT. Brain (1.60 ml) and pituitary $(0.42 \mathrm{ml}$ ) supernatants (S2 in Methods) were applied on an HVE plate, after a Sep-Pak step, and electrophoresed as described in the legend to Figure 5 , except that in this experiment $100 \mu \mathrm{l}$ (brain) and $2 \mu \mathrm{l}$ (neural lobe) aliquotes of the $500 \mu \mathrm{l}$ cellulose $\mathrm{HCl}$ extract were analyzed for OT and OT-X immunoreactivity. OT immunoreactivity $\left(\mathrm{O}_{-}-\mathrm{O}\right)$ was determined using OT-MM antiserum (1:100,000), and OT-X immunoreactivity $(\mathrm{O}-\mathrm{O})$ was calculated from the difference between the immunoreactivities of OT-VA-17 (1:60,000) and OT-MM. Electrophoretic positions of standards (arrows) were visualized by fluorescamine and measured by means of RIA as described in Methods. Value of OT-GK was corrected for the cross-reactivity of anti-OT-VA17 with OT-GK. Abbreviations: $O T$-G, OT-glycine; $O T$-GK, OT-glycine-lysine; $O T$-GKR, OTglycine-lysine-arginine (see Fig. 1).

Gly-Lys-Arg and OT-Gly-Lys, and appearance of OT-Gly, which is resistant to the enzymatic activity. Figure 7 shows that treatment of brain extracts with CP-B caused both extended forms (OT-Gly-Lys and OT-Gly-Lys-Arg) in the brain extract to disappear and add to the immunoreactivity of the OT/OT-Gly peak as expected.

\section{Evaluation of precursor content and total AVP and OT during development}

In the above sections we demonstrated that the extent of processing of the OT precursor (Pro-OT) to peptide forms was much more immature than that of the AVP precursor (Pro-AVP) during embryonic development and that partially processed (but cleaved) forms of OT, in contrast to AVP, were abundant even during postnatal stages (Fig. 4). In addition, the absolute content of all AVP peptide forms were 5- to 10-fold higher than those of OT peptide forms throughout the embryonic period (Fig. 3; Tables 3,4$)$. One possible explanation for the dominance of cleaved AVP could be that Pro-OT is not proteolytically cleaved with the efficiency of cleavage of Pro-AVP in vivo. In order to check for this possibility, the quantities of Pro-AVP and ProOT were independently analyzed at the various developmental stages and compared to levels of the cleaved hormone. Since direct RIA determinations of prohormone content are not tech- nically feasible at present, we used an indirect method (see Methods). This method was based on the fact that trypsin treatment of the precursor releases the peptide hormones from their N-termini, which can then be detected by antibodies that react with C-terminally extended forms (see Fig. 1 for expected tryptic cleavage products of Pro-AVP and Pro-OT). The use of such an approach required the separation of the prohormones from the cleaved peptides, and this was done by TCA precipitation of the precursors and analysis of hormone immunoreactivity in the P2 pellet after trypsin treatment (see Methods).

The results of the above experiment are shown in Tables 3 and 4, together with a quantitative summary of the AVP and OT immunoreactives found in precursors and cleaved peptide forms in brain and pituitary at various stages of development. Several conclusions are apparent from the analysis of precursor immunoreactivity. (1) As might be expected, the detectable immunoreactivity in precursor form precedes that detectable in cleaved peptide forms by 1 d (i.e., on E1 5 for Pro-AVP and E17 for Pro-OT). (2) At no time in development does the pituitary contain measurable precursor immunoreactivity (data not shown), and both peptides found in this tissue are always predominantly in the amidated form. (3) Cleavage of both precursors to peptide products occurs early in development, although the ratio of the Pro-OT to OT peptides in brain is generally 
higher than that of the Pro-AVP/AVP peptide during fetal life (e.g., for OT the ratio at E21 is 1.9 , whereas for AVP at this time the ratio is 0.30 ). The significance of this observation is unclear and could reflect either a difference in efficiency of precursor proteolytic processing, a difference in storage of cleaved peptides in brain, or both. It is interesting, however, that this difference in ratio persists into late postnatal stages (e.g., at PN21 the OT ratio is 0.45, whereas the AVP ratio is 0.06). (4) Even accounting for the contributions of precursor immunoreactivities, the total AVP immunoreactivity in the brain and pituitary is 5-10 times greater than that of OT throughout fetal life. These values approach equivalence during the later stages of postnatal development and equality by PN40 (Tables 3,4 ).

\section{Discussion}

In this paper, we have presented a quantitative analysis of the ontogeny of AVP and OT precursor biosynthesis and posttranslational processing in the rat CNS. Previous quantitative studies of AVP and OT ontogeny indicated that OT was not present in the brain during early fetal development (see introduction), whereas immunocytochemical studies from our laboratory, using monoclonal antibodies that cross-reacted with the neurophysin moiety in the AVP and OT precursors, indicated that neurons containing Pro-AVP and Pro-OT immunoreactivity were present as early as E16 and continued to increase throughout embryonic development (Whitnall et al., 1985). This apparent contradiction between the previous quantitative RIA studies and the qualitative immunochemical study cited above prompted us to reexamine this issue by an RIA analysis that could quantitatively assess the precursors and the intermediate and fully processed (amidated) forms for both AVP and OT. The results are in concordance with the immunocytochemical findings of an early expression of the OT gene in the brain and support the hypothesis that the Pro-OT precursor is incompletely processed during fetal life to unamidated forms of OT. In addition to resolving the apparent contradiction in the literature on this subject, these quantitative data have uncovered significant differences in the biosynthetic states of the AVP and OT neurons during fetal development.

The differences we have found include (1) different steadystate levels of the precursors and peptides, with AVP neurons far exceeding (5- to 10-fold) OT neurons in this regard; (2) different commitments to posttranslation processing mechanisms, so that AVP neurons produce amidated AVP peptide products as early as E16 (Table 3), whereas the complete processing of OT first occurs $1 \mathrm{~d}$ prior to birth (E21; Table 4); and (3) a significantly earlier and more abundant axonal transport of AVP peptides (in comparison to OT peptides) to the posterior pituitary (i.e., AVP first detected at E18, and OT at E21 in the posterior pituitary), and by E21 there is about 20 -fold more AVP than OT in this neurohemal organ. It is clear from these observations that the AVP neurons are significantly more precocious than OT neurons during development.

The estimates of first detection of AVP and OT gene expression in the brain by the RIA methods we have used compare favorably with alternative (but qualitative) methods. Immunocytochemical assays first detected AVP- and OT-expressing neurons at E16 (Whitnall et al., 1985), and in situ hybridization histochemical techniques have detected AVP mRNA (OT mRNA was not studied) at El 6 at the earliest (Reppert and Uhl, 1987). Our RIA analysis first detected Pro-AVP at E15 a day earlier (Table 3) and Pro-OT at E17 a day later (Table 4) than

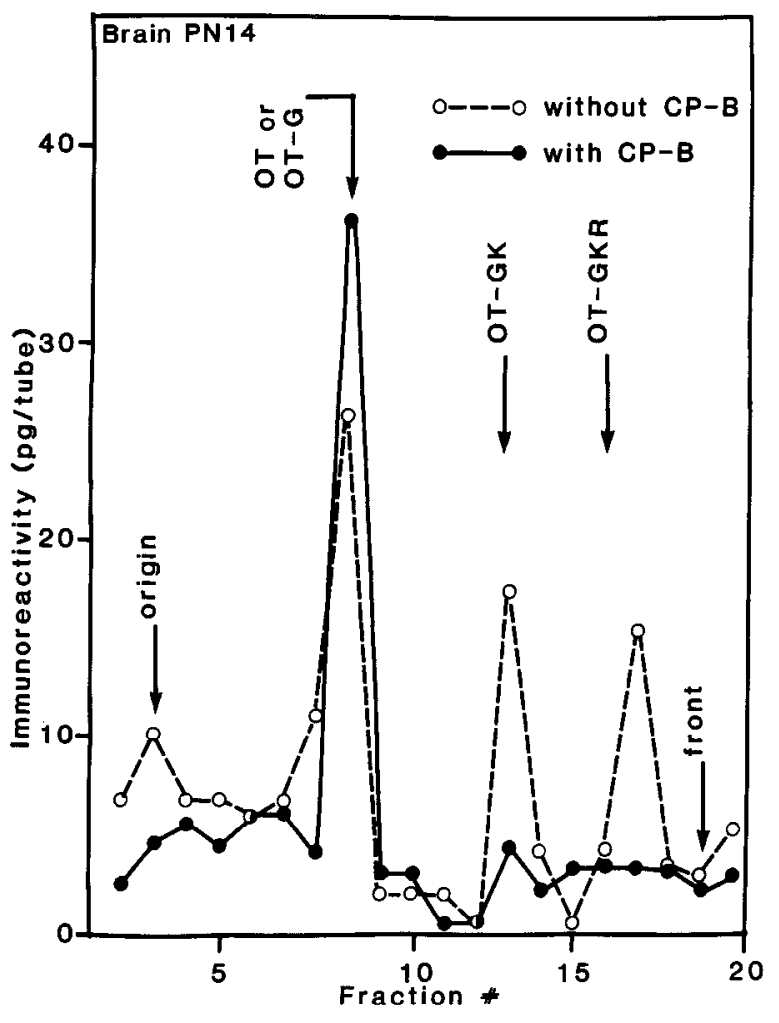

Figure 7. HVE of a brain extract from postnatal day 14 before and after carboxypeptidase B (CP-B) treatment. Two milliliters of brain extract (S2 in Methods) were lyophilized, resuspended in $500 \mu \mathrm{l}$ of CP-B buffer ( $50 \mathrm{~mm}$ Tris- $\mathrm{HCl}, \mathrm{pH} 8.0$ ), and the sample was incubated in the presence and absence of CP-B $(40 \mu \mathrm{g} / \mathrm{ml})$ for $2 \mathrm{hr}$ at $37^{\circ} \mathrm{C}$. The cnzymatic reaction was stopped with $0.1 \mathrm{~N} \mathrm{HCl}$ (final concentration), and the treated and untreated samples were passed through a Sep-Pak column and electrophoresed as described in Methods. Immunoreactivity was determined using $100 \mu \mathrm{l}$ of the cellulose extract and OT-VA 17 antiserum $(1: 60,000)$. Values were corrected as described in the legend to Figure 6 , and standard peptide markers were visualized as described in the legend to Figure 5.

the immunocytochemical studies. Given the low levels of ProOT expressed in fetal rat brain, it is perhaps not surprising that immunocytochemistry (a technique that can detect immunoreactivity in single secretory vesicles; see Ben-Barak et al., 1985) is more sensitive than the RIA method. What is surprising is that Pro-AVP could be detected by RIA on E15, a day before immunocytochemical detection. Although both the AVP and OT neurons are capable of synthesizing precursors on about the same embryonic day, it is clear that the level of gene expression is much greater throughout fetal life in the AVP neurons. This is reflected by the 10-fold greater content of AVP precursors and peptide products than OT (compare Tables 3 and 4). Although no comparisons of OT and AVP mRNA in early fetal brain are available, Van Tol (1987) has shown using Northern blot analysis of PVN and SON mRNA that at E20 in the rat hypothalamus, AVP mRNA is significantly greater than OT mRNA, consistent with the quantitative RIA data on translated products presented here.

It is known that the magnocellular neurons in the rat SON and PVN undergo their terminal cell divisions between E12 and E15 (Ifft, 1972; Altman and Bayer, 1978a, b), so that the differences found in biosynthetic levels and posttranslational processing (from E15 to E21) are not likely to be the result of a 
delayed neurogenesis of OT neurons. Instead, it appears that the AVP and OT neurons have differentially regulated developmental programs, at least with respect to peptide biosynthesis, during fetal life. In addition, Whitnall et al. (1985) suggested a differential rate of axonal outgrowth between the OT and AVP neurons, which was indicated by abundant Pro-AVP-containing axons in the internal zone of the median eminence at E21, whereas very few Pro-OT axons could be found in this region of the hypothalamoneurohypophysial tract at that time. This interpretation is consistent with our findings of a $3 \mathrm{~d}$ lag between AVP and OT appearance in the posterior pituitary (the site of axon termination) and of the 20 -fold greater content of AVP versus OT in the pituitary at E21 (Figs. 2 and 3, Tables 3 and 4).

The systematic developmental delay observed in posttranslational processing of the OT peptides during fetal life is particularly interesting. Amidated OT is not produced until E21, and even neonatal brain contains substantial OT-GKR intermediates (Fig. 6). Presumably this block is occurring at the carboxypeptidase-B-like and $\alpha$-amidating enzymatic steps in processing (Gainer et al., 1985). Since these processing steps proceed to completion in the AVP neurons, this "regulation" appears to be cell-specific and is not due to a general developmental lag in these processing mechanisms in the hypothalamus. It will be interesting, in the future, to determine whether gene expression of these enzymes is delayed in OT neurons versus AVP neurons. Regulation at the level of processing has also been reported for a variety of other peptide-synthesizing cells (Eipper and Mains, 1978, 1981; Mains and Eipper, 1979, 1981; Krieger et al., 1980; Seizinger et al., 1984; Kream et al., 1985; Sato and Mains, 1985; Rehfeld, 1986).

This developmental lag in OT processing gave us a unique opportunity to observe the nature of the proteolytic cleavage mechanism as it occurs in vivo. The presence of a stable OTGly-Lys-Arg intermediate (Fig. 6) has significance for the mechanism of prohormone processing since it indicates that the prohormone converting enzyme cleaves at the C-terminus of the $\mathrm{Arg}^{12}$ in the commonly found paired basic cleavage site (LysArg) in vivo (see Fig. 1). While this conclusion is clear for the OT-Gly-Lys-Arg intermediate, the occurrence of stable OT-GlyLys and OT-Gly intermediates (Figs. 6 and 7) is not unequivocal with respect to this point since these intermediates could have been generated either directly by the endopeptidase or, alternatively, by a carboxypeptidase-B action following cleavage. In any case, to our knowledge, this is the first experimental evidence for the utilization of the carboxyl side of the Arg in the Lys-Arg pair as a cleavage site in any neuropeptide prohormone in vivo. In addition, this is consistent with our previous report that the AVP-precursor is cleaved principally at the carboxyl side of the $\mathrm{Arg}^{12}$ in vitro by a putative prohormone converting enzyme that was isolated from the neural lobe (Parish et al., 1986) and that this same site is cleaved in vitro by neural lobe endopeptidase in a Pro-OT ${ }_{1-18}$ synthetic peptide (Clamagirand et al., 1986).

It is intriguing that fully amidated AVP is abundantly present in the developing rat brain and pituitary at least 3 weeks before the AVP has its prominent antidiuretic effects on the kidney (approximately at PN20, at the end of the suckling period; $\mathrm{Ra}$ jerison et al., 1976). Since AVP receptors have been reported to be present in the embryonic brain, it has been proposed previously that AVP may play a role as a trophic factor in the brain during embryonic and early postnatal development (see
Boer, 1987). Similar arguments have been put forth for other neuropeptides (e.g., POMC-derived peptides, TRH and VIP), which are reputed to influence neuronal proliferation, migration, differentiation, and the organization of functional pathways during brain development (see Stratton et al., 1976; Swaab et al., 1978; Aranda and Stern, 1983; Lauder, 1983; Brenneman et al., 1985; Handelmann, 1985; Brenneman and Eiden, 1986; Zagon and McLaughlin, 1986). The observation that Np-AVP was mitogenic for cultured hypothalmic glia (Worley and Pickering, 1984) may be related to the early arrival of AVP peptides in the posterior pituitary. The initiation of pituicyte (i.e., neural lobe astrocyte) differentiation has been correlated with the first appearance of neurosecretory (presumably AVP; see Fig. 3 and Table 3) axons in the neural lobe (Dellman and Sikora, 1981), and hence, it is possible that pituicyte differentiation is, in part, mediated by Pro-AVP derived peptides. The biological significance of the delayed development in OT biosynthesis, processing, and axonal transport is unclear at present. One possibility is that the extended forms of OT may themselves play a role in fetal brain development. Alternatively, the OT may bind to the AVP receptors in fetal brain and pituitary but not possess the biological activity of the AVP and, thereby, could potentially act as a natural antagonist. Further investigation is necessary not only to uncover the biological significance of this differential regulation of biosynthesis and processing in the developing AVP and OT neurons, but also the molecular mechanisms that underlie it.

\section{References}

Altman, J., and S. A. Bayer (1978a) Development of the diencephalon in the rat. I. Autoradiographic study of the time of origin and settling patterns of neurons in the hypothalamus. J. Comp. Neurol. 182:945972.

Altman, J., and S. A. Bayer (1978b) Development of the diencephalon in the rat. II. Correlation of the embryonic development of the hypothalamus with time of origin in its neurons. J. Comp. Neurol. 182: 973-994.

Altstein, M., and H. Gainer (1986) Oxytocin and vasopressin precursors are differentially processed in developing rat brain. Soc. Neurosci. Abstr. 12: 287.2.

Altstein, M., M. H. Whitnall, S. House, S. Key, and H. Gainer (1988) An immunochemical analysis of oxytocin and vasopressin processing in vivo. Peptides 9:87-105.

Aranda, J. V., and L. Stern (1983) Clinical aspects of developmental pharmacology and toxicology. Pharmacol. Ther. 20: 1-51.

Ben-Barak, Y., J. T. Russell, M. H. Whitnall, K. Ozato, and H. Gainer (1985) Neurophysin in the hypothalamo-neurohypophysial system: I. Production and characterization of monoclonal antibodies. J. Neurosci. 5: 81-97.

Boer, G. J. (1987) Development of vasopressin systems and their functions. In Vasopressin, Principles and Properties, D. M. Gash and G. J. Boer, eds., pp. 117-160, Plenum, New York.

Boer, G. J., J. Dogterom, and H. F. Pronker (1980a) Pituitary content of oxytocin, vasopressin and alpha-melanocyte-stimulating hormone in the fetus of the rat during labour. J. Endocrinol. 86: 221-229.

Boer, G. J., R. M. Buijs, D. F. Swaab, and G. J. DeVries (1980b) Vasopressin and the developing rat brain. Peptides (Suppl. 1) 1:203209.

Boer, G. J., D. F. Swaab, H. B. M. Uylings, K. Boer, R. M. Buijs, and D. N. Velis (1980c) Neuropeptides in rat brain development. Prog. Brain Res. 53: 207-227.

Brenneman, D. E., and L. E. Eiden (1986) Vasoactive intestinal peptide and electrical activity influence neuronal survival. Proc. Natl. Acad. Sci. USA 83: 1159-1162.

Brenneman, D. E., L. E. Eiden, and R. E. Siegel (1985) Neurotrophic action of VIP on spinal cord cultures. Peptides 6: 35-39.

Buijs, R. M., D. N. Velis, and D. F. Swaab (1980) Ontogeny of vasopressin and oxytocin in the fetal rat: Early vasopressinergic innervation of the fetal brain. Peptides $1: 315-324$. 
Castel, M., H. Gainer, and H. D. Dellmann (1984) Neuronal secretory systems. Int. Rev. Cytol. 88: 303-459.

Choy, V. J., and W. B. Watkins (1979) Maturation of the hypothalamo-neurohypophysial system. I. Localization of neurophysin, oxytocin and vasopressin in the hypothalamus and neural lobe of the developing rat brain. Cell Tissue Res. 197: 325-336.

Clamagirand, C., M. Camier, H. Bousetta, C. Fahy, A. Morel, P. Nicolas, and P. Cohen (1986) An endopeptidase associated with bovine neurohypophysis secretory granules cleaves pro-oxytocin/neurophysin peptide at paired basic residues. Biochem. Biophys. Res. Commun. 134: 1190-1196.

Dellmann, H. D., and K. Sikora (1981) Pituicyte fine structure in the developing neural lobe of the rat. Dev. Neurosci. 4: 89-97.

Douglas, J., O. Civelli, and E. Herbert (1984) Polyprotein gene expression: Generation of diversity of neuroendocrine peptides. Annu. Rev. Biochem. 53: 665-715.

Eipper, B. A., and R. E. Mains (1978) Analysis of the common precursor to corticotropin and endorphin. J. Biol. Chem. 253: 57325744.

Eipper, B. A., and R. E. Mains (1981) Further analysis of post-translational processing of a $\beta$-endorphin in rat intermediate pituitary. $\mathrm{J}$. Biol. Chem. 256: 5689-5695.

Gainer, H. (1983) Precursors of vasopressin and oxytocin. Prog. Brain Res. 60: 205-215.

Gainer, H., J. T. Russell, and Y. P. Loh (1985) The enzymology and intracellular organization of peptide precursor processing: The secretory vesicle hypothesis. Neuroendocrinology 40: 171-184.

Handelmann, G. E. (1985) Neuropeptide effects on brain development. J. Physiol. (Paris) 80: 268-274.

Ifft, J. D. (1972) An autoradiographic study of the time of final division of neurons in rat hypothalamic nuclei. J. Comp. Neurol. 144: 193204.

Ivell, R., and D. Richter (1984) Structure and comparison of the oxytocin and vasopressin genes from rat. Proc. Natl. Acad. Sci. USA 81: 2006-2010.

Ivell, R., H. Schmale, and D. Richter (1983) Vasopressin and oxytocin precursors as model prohormones. Neuroendocrinology 37: 23562359.

Khachaturian, H., and J. R. Sladek (1980) Simultaneous monoamine histofluorescence and neuropeptide immunocytochemistry: III. Ontogeny of catecholamine varicosities and neurophysin neurons in the rat supraoptic and paraventricular nuclei. Peptides 1: 77-95.

Kream, M. R., T. A. Shoenfeld, R. Mancuso, A. N. Clancy, W. ElBermani, and F. Macrides (1985) Precursor forms of substance $P$ (SP) in nervous tissue: Detection with antisera to SP, SP-Gly and SPGly-Lys. Proc. Natl. Acad. Sci. USA 82: 4832-4836.

Krieger, D. T., A. S. Liotta, M. J. Brownstein, and E. A. Zimmerman (1980) ACTH, $\beta$-lipotropin and related peptides in brain, pituitary and blood. Recent Prog. Horm. Res. 36: 277-344.

Krisch, B. (1980) Electron microscopic immunocytochemical investigation of the postnatal development of the vasopressin system in the rat. Cell Tissue Res. 205: 453-471.

Land, H., G. Schutz, H. Schmale, and D. Richter (1982) Nucleotide sequence of cloned c-DNA encoding bovine arginine vasopressin neurophysin II precursor. Nature 295: 299-303.

Land, H., M. Grez, S. Ruppert, H. Schmale, M. Rehbien, D. Richter, and G. Schutz (1983) Deduced amino acid sequence from the bovine oxytocin neurophysin I precursor c-DNA. Nature 302: 342-344.

Lauder, J. M. (1983) Hormonal and humoral influences on brain development. Psychoneuroendocrinology 8: 121-155.

Leclerc, R., and G. Pelletier (1977) Ontogeny of neurophysin in the rat pituitary gland. An electron microscope immunohistochemical study. Brain Res. 129: 275-281.

Loh, Y. P., M. J. Brownstein, and H. Gainer (1984) Proteolysis in neuropeptide processing and other neural functions. Annu. Rev. Neurosci. 7: 189-222.

Mains, R. E., and B. A. Eipper (1979) Synthesis and secretion of corticotropins, melanotropins, and endorphins by rat intermediate pituitary cells. J. Biol. Chem. 254: 7885-7894.

Mains, R. E., and B. A. Eipper (1981) Differences in the post-translational processing of $\beta$-endorphin in rat anterior and intermediate pituitary. J. Biol. Chem. 256: 5683-5688.

Mandez, E., and C. Y. Lai (1973) Reaction of peptides with fluorescamine on paper after chromatography or electrophoresis. Anal. Biochem. 65: 281-292.

Moore, G., A. Lutterodt, G. Burford, and K. Lederis (1977) A highly specific antiserum for arginine vasopressin. Endocrinology 101:14211435.

Morris, M., S. W. Stevens, and M. R. Adams (1980) Plasma oxytocin during pregnancy and lactation in the Cynomolgus monkey. Biol. Reprod. 23: 782-787.

Parish, D. C., R. Tuteja, M. Altstein, H. Gainer, and Y. P. Loh (1986) Purification and characterization of a paired basic residue specific prohormone converting enzyme from bovine pituitary neural lobe secretory vesicles. J. Biol. Chem. 261: 14392-14397.

Rajerison, R. M., D. Butlen, and S. Jard (1976) Ontogenic development of antidiuretic hormone receptors in rat kidney: Comparison of hormonal binding and adenylate cyclase activation. Mol. Cell. Endocrinol. 4: 271-285.

Rehfeld, J. F. (1986) Accumulation of nonamidated preprogastrin and preprocholecystokinin products in porcine pituitary corticotrophs. $\mathrm{J}$. Biol. Chem. 261: 5841-5847.

Reppert, S. M., and G. R. Uhl (1987) Vasopressin messenger ribonucleic acid in supraoptic and suprachrasmatic nuclei: Appearance and cicadian regulation during development. Endocrinology 120:24832487.

Sato, S. M., and R. Mains (1985) Post-translational processing of proadrenocorticotropin/endorphin derived peptides during postnatal development in the rat pituitary. Endocrinology 117: 773-786.

Seizinger, B. R., C. Grimm, V. Hollt, and A. Herz (1984) Evidence for a selective processing of proenkephalin B into different opioid peptide forms in particular regions of rat brain and pituitary. J. Neurochem. 42: 447-457.

Sinding, C., A. G. Robinson, S. M. Seif, and P. G. Schmid (1980) Neurohypophysial peptides in the developing rat fetus. Brain Res. 195: $177-186$.

Sladek, C. D., D. M. Gash, H. Khachaturian, D. E. Scott, and J. R. Sladek, Jr. (1980) Maturation of the supraoptic nucleus: A multidisciplinary analysis. Peptides $1:$ 51-67.

Sofroniew, M. V. (1985) Vasopressin, oxytocin and their related neurophysins. In Handbook of Chemical Neuroanatomy, Vol. 4, Pt. I, A. Bjorklund and T. Hökfelt, eds., pp. 93-165. Elsevier, Amsterdam.

Stratton, L. O., C. A. Gibson, K. G. Kolar, and A. J. Kastin (1976) Neonatal treatment with TRH affects development, learning and emotionality in the rat. Pharmacol. Biochem. Behav. (Suppl. 1) 5: 65-67.

Swaab, D. F., G. J. Boer, and M. Vissar (1978) The fetal brain and intrauterine growth. Postgrad. Med. J. (Suppl. 1) 5: 63-73.

Van Tol, H. H. M. (1987) Regulation of vasopressin and oxytocin gene expression in the hypothalamo-neurophypophyseal system of the rat. Ph.D. thesis, University of Utrecht, The Netherlands.

Watkins, W. B., and V. J. Choy (1979) Maturation of the hypothalamo-neurophypophysial system. II. Neurophysin, vasopressin and oxytocin in the median eminence of the developing rat brain. Cell Tissue Res. 197: 337-346.

Whitnall, M. H., S. Key, Y. Ben-Barak, K. Ozato, and H. Gainer (1985) Neurophysin in the hypothalamo-neurohypophysial system. II. Immunocytochemical studies of the ontogeny of oxytocinergic and vasopressinergic neurons. J. Neurosci. 5: 98-109.

Worley, R. T. S., and B. T. Pickering (1984) Non neuronal cells of rat hypothalamus in dissociated cell culture. Cell Tissue Res. 237: 161-168.

Zagon, I. S., and P. J. McLaughlin (1986) Opioid antagonist-induced modulation of cerebral and hippocampal development: Histological and morphometric studies. Brain Res. 393: 233-246. 